\title{
RESPONSE ANALYSIS OF BURIED PIPELINE SUBJECTED TO REVERSE FAULT DISPLACEMENT IN ROCK STRATUM
}

\begin{abstract}
Summary
Response analysis of the buried pipeline subjected to reverse fault displacement is very important for design, detection and protection of buried pipelines. This paper looks at the buckling behavior of a buried pipeline subjected to reverse fault displacement in the rock stratum. Effects of internal pressure, wall thickness, fault displacement and burial depth on the buckling mode and the axial strain of the buried pipeline are discussed. The results show that there are two buckling locations on the buried pipeline subjected to reverse fault displacement in the rock stratum and that the buckling modes of the buried pipes with different internal pressures are different. The two buckling locations are not symmetrically distributed along the fault plane. The buckling mode ranges from collapse to wrinkle as the internal pressure increases. The buckling phenomenon becomes more serious as the fault displacement increases, and the shape of the deformation curve changes from the S-shape to the Z-shape. The process of pipeline deformation can be divided into three stages. There is no buckling in the first stage. The second stage is a transition stage, buckling appears on the buried pipeline. Buckling is more serious in the third stage. Fault displacement has a small effect on the maximum strain position of the buried pipeline. The deformation curve of the buried pipeline is smoother as the wall thickness increases. The maximum axial strain of pressure pipes first increases and then decreases as the wall thickness increases.
\end{abstract}

Key words: $\quad$ steel pipeline, reverse fault, rock stratum, finite element method, buckling

\section{Introduction}

Buried pipelines are the main mode of transportation of oil and gas and important part of infrastructure like city traffic, communication, and water supply. The structural safety and reliability problem related to buried pipelines has been receiving a lot of attention. The reverse fault, caused by earthquakes, is one of the threats to buried pipelines. Buried pipelines are easily destroyed in earthquakes, which may result in the functional damage or paralysis of a pipeline system [1]. Permanent ground deformation caused by a fault is one of the main reasons for the failure of buried pipelines [2]. For example, there were 29 damage cases on 14 pipelines in the Liaohe oilfield in the 1975 Haicheng earthquake in China. In the Tangshan earthquake in 1976, four destruction cases occurred in the Jing-qin pipeline which were caused by a fault, and ten thousand tons of crude oil were spilled [3], which not only caused 
serious waste of resources, but also polluted the farmland and the river. One million square meters of buildings were destroyed by the fire which resulted from the damaged pipelines in the 1991 Northridge earthquake in the United States [4]. Therefore, the response analysis of buried pipelines subjected to reverse fault displacement is very important for the design, detection and protection of buried pipelines.

In 1975, Newmark and Hall put forward a method for analyzing the buried pipeline in the fault area by using a small displacement model of static earth pressure and static friction force [5]. Kennedy improved the Newmark-Hall method by considering the pipeline-soil interaction, and the bending strain of the pipeline was calculated by using the large displacement theory [6]. A deformed pipeline was simplified to a large deformation beam and an elastic foundation beam by Wang who considered the pipeline's bending stiffness and the pipeline-soil interaction, and the stress and strain distributions of the pipeline were gained by using a three-line steel model [7]. In these studies, pipelines buried in the soil mass layer were investigated, but the conditions of rock stratum were not considered. Long-distance pipelines may cross mountains, rivers, marshes, plateaus, cities, permafrost areas, and the layers may be soil stratum or rock stratum. Mechanical properties of buried pipelines in the soil stratum are different from those in the rock stratum. In addition, compressive stress caused by fault motion may cause buckling of the buried pipeline either in the beam mode or in the shell mode. Thus, earlier various simplified methods prove to be inadequate for the analysis of pipelines crossing a reverse fault. Numerical techniques based on the finite element method allow for a detailed analysis to be performed.

In this paper, the buckling behavior of a buried pipeline subjected to reverse fault displacement is investigated by using the finite element method and considering the pipeline-soil interaction in the rock stratum. Effects of internal pressure, wall thickness, fault displacement and burial depth on the buckling mode and axial strain of the buried pipeline are discussed.

\section{Finite element model}

In this paper, the fault dip angle $\beta=45^{\circ}$ is defined. Fig. 1 shows finite element models of a buried pipeline crossing the fault stratum. Four-node reduced-integration shell elements are employed for meshing the pipeline, and eight-node reduced-integration elements are used to simulate the backfill soil and the stratum. The pipeline diameter is $D=0.81 \mathrm{~m}$, and the wall thickness is $t=8 \mathrm{~mm}$. The burial depth is equal to $2 \mathrm{~m}$, which is in accordance with the pipeline engineering practice. The stratum length in the $x$ direction is equal to 75 pipeline diameters, whereas the dimensions in the directions $y$ and $z$ are equal to 6 and 12 times the pipeline diameter, respectively. A total of 42 shell elements around the cylinder circumference in this central part have been found to be adequate to achieve convergence of the solution.

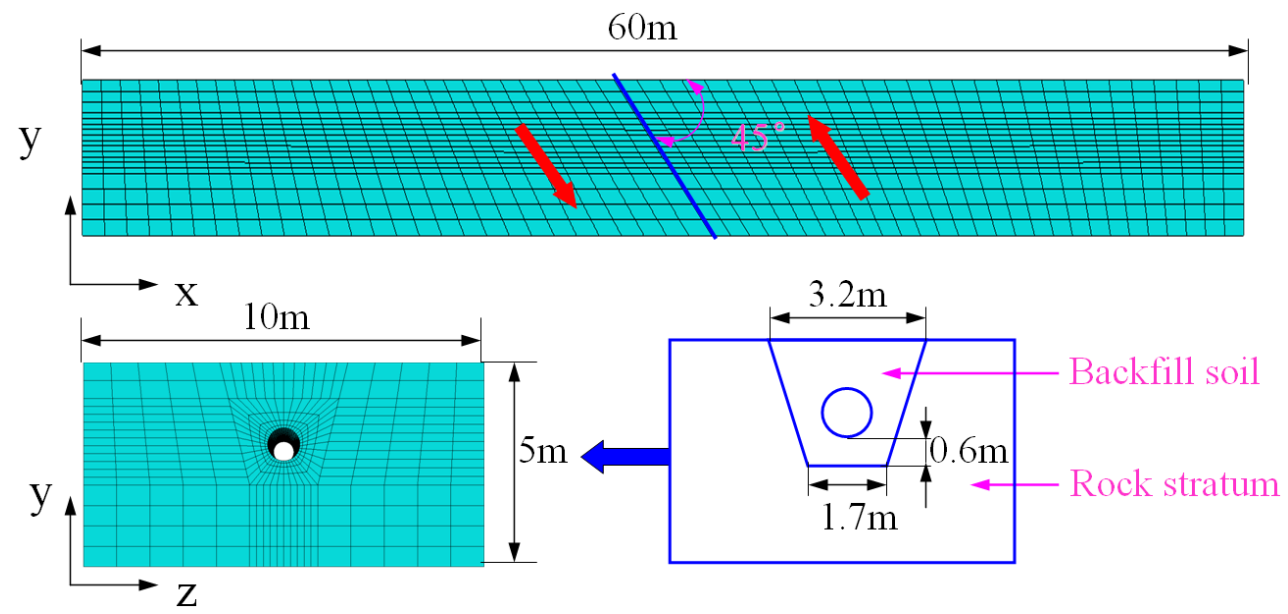

Fig. 1 Finite element models of buried pipeline, backfill soil and rock stratum 
The fault plane divides the stratum into two blocks of equal size. The analysis is conducted in two steps as follows: first, gravity loading is applied to the whole model and internal pressure acts on the inner wall of the pipeline [8]. Subsequently, reverse fault displacement is imposed. The nodes on the two sides of the two blocks remain fixed in the $z$ direction. Uniform displacement is imposed at the bottom nodes of the first block along the fault positive direction, and it is also imposed at the bottom nodes of the second block along the fault negative direction.

A large-strain plasticity model with isotropic hardening is employed for the steel pipeline material. Mechanical behaviour of soil and rock materials is described by an elasticperfectly plastic Mohr-Coulomb constitutive model, characterized by the cohesion $c$, the friction angle $\phi$, the elastic modulus $E$, and Poisson's ratio $v$ [9]. The dilation angle is assumed equal to zero for the cases considered in this paper. In this paper, the backfill soil is loess, the cohesion $c_{1}=24.6 \mathrm{kPa}$, friction angle $\phi_{1}=11.7^{\circ}$, elastic modulus $E_{1}=33 \mathrm{MPa}$, density $\rho_{1}=1400 \mathrm{~kg} / \mathrm{m}^{3}$ and Poisson's ratio $v_{1}=0.44[10]$. The stratum is limestone rock, $c_{2}=6.72 \mathrm{MPa}$, $\phi_{2}=42^{\circ}, E_{2}=28.5 \mathrm{GPa}, \rho_{2}=2090 \mathrm{~kg} / \mathrm{m}^{3}$ and $v_{2}=0.29$. The interface between the outer surface of the pipeline and the surrounding soil is simulated with a contact algorithm, which allows separation of the pipeline and soil, and accounts for interface friction, through an appropriate friction coefficient $\mu=0.3$ [11]. Numerical results are obtained for X65 steel pipelines. The yield stress equals $\sigma_{\mathrm{y}}=448.5 \mathrm{MPa}$ [12]. Young's modulus of the steel material is $210 \mathrm{GPa}$, Poisson's ratio is 0.3 and density is $7800 \mathrm{~kg} / \mathrm{m}^{3}$. Considering a safety factor equal to 0.72 [13], the maximum operating pressure $P_{\max }$ of this pipeline can be given by the expression $P_{\max }=0.72 \times\left(2 \sigma_{y} t / D\right)=5.65 \mathrm{MPa}[14]$.

\section{Results and Discussions}

\subsection{Internal pressure effect}

Fault displacement of $2.4 \mathrm{~m}$, the von Mises stress distribution and buckling modes of the buried pipeline with different internal pressures are shown in Fig. 2. On the buried pipeline there are two buckling locations on the sides of the fault plane. But they are not symmetrically distributed along the fault plane. The bending moment is applied to the buried pipeline subjected to the reverse fault displacement. The lower part of section A is compressed, and the upper part is extruded, whereas the lower part of section B is extruded, and the upper part is compressed. Because the rock stratum is located in the lower part of the buried pipeline, and soil is located in the upper part of the buried pipeline. The buckling location and the stress distribution of sections A and B are different. The stress of the pipeline away from the fault plane increases gradually as the internal pressure increases. The stress change of the pipeline around the fault plane is more violent.

Buckling modes of the buried pipes with different internal pressures are different. The buckling modes of sections A and B are also different. In Fig. 2, the internal pressure has a great effect on the buckling mode of the buried pipeline subjected to the reverse fault displacement. When the internal pressure $P \leq 0.4 P_{\max }$, the plastic strain of section A is greater than that of section $\mathrm{B}$. When $P>0.4 P_{\max }$, the plastic strain of section $\mathrm{A}$ is smaller than that of section B. When the internal pressure is small, collapse appears. Wrinkling appears as the internal pressure increases. When the internal pressure is $P_{\max }$, there are two wrinkles in section A, but one wrinkle in section B. Therefore, the buried pipes with different internal pressures have different buckling modes. If the strain is greater than the ultimate strain of the pipe material, rupture will occur. Then, leakage of liquid may result in explosion or environmental pollution. 


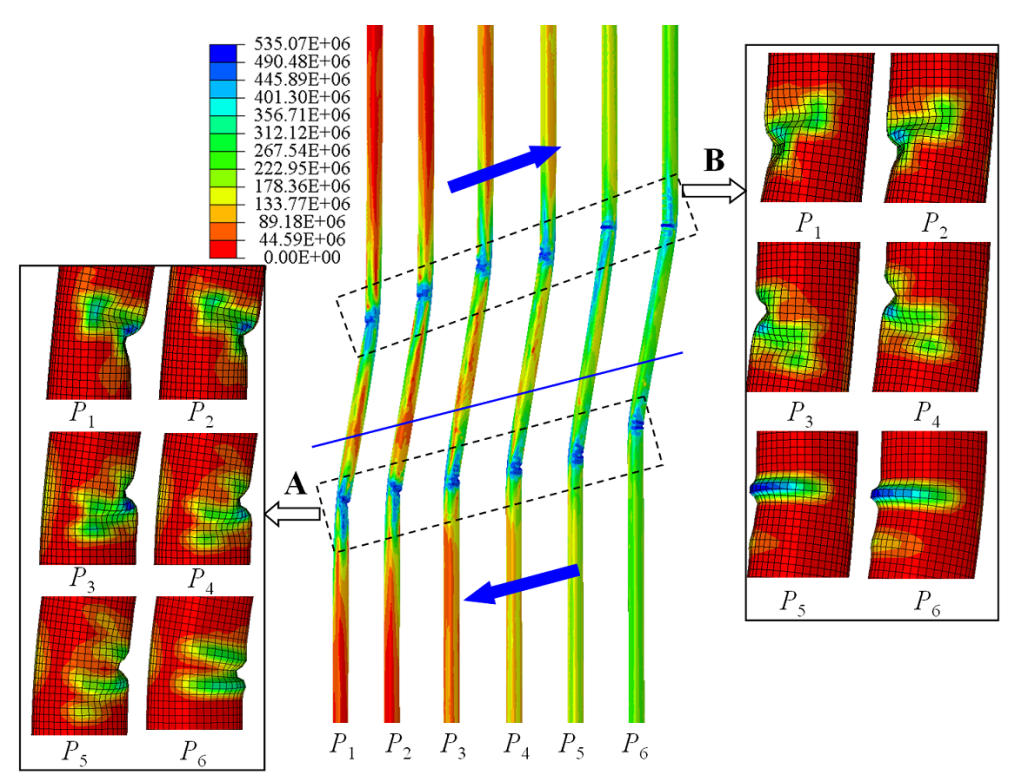

Fig. 2 Stress distribution and buckling modes of buried pipes with different internal pressures. $P_{1}=0$ (nonpressure), $P_{2}=0.2 P_{\max }, P_{3}=0.4 P_{\max }, P_{4}=0.6 P_{\max }, P_{5}=0.8 P_{\max }, P_{6}=P_{\max }$.

The maximum axial strain of the buckling locations under different internal pressures is shown in Fig. 3. The axial strain of section B of the pipeline increases as the internal pressure increases. But there are two volatilities for the axial strain curve of section A. This is closely related to the buckling mode. When the internal pressure $P \leq 0.4 P_{\max }$, the maximum axial strain of section A is greater than that of section B. But when the internal pressure $P>0.4 P_{\max }$, the axial strain of section B is greater. Therefore, when the internal pressure is small, the most at risk part is section $\mathrm{A}$, but as the internal pressure increases the most at risk part becomes section B .

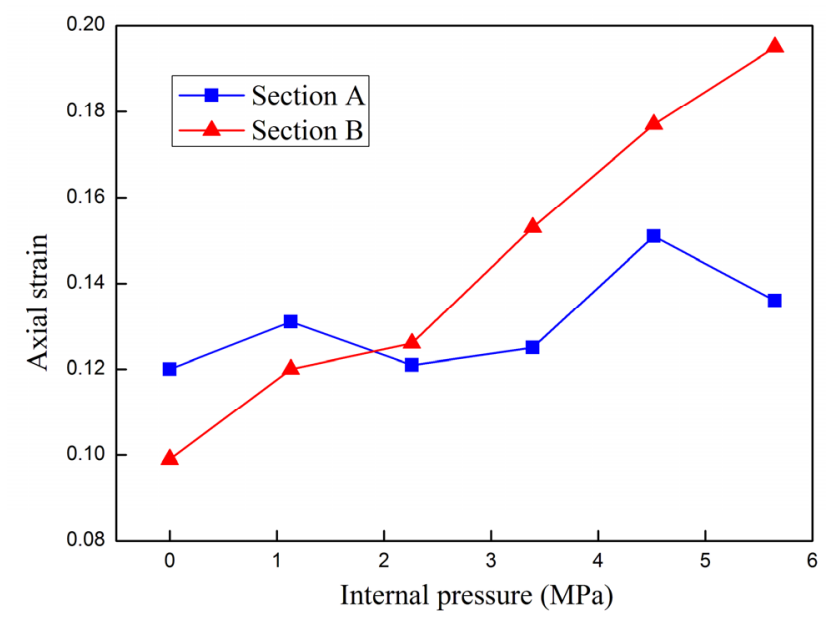

Fig. 3 Axial strain of buckling locations under different internal pressures

\subsection{Fault displacement effect}

Von Mises stress distribution and buckling modes of the buried pipeline subjected to different fault displacements are shown in Fig. 4. In Fig. 4(a), the buckling phenomenon becomes more serious as the fault displacement increases. When the fault displacement is $0.6 \mathrm{~m}$, there is no buckling, deformation of the buried pipeline is the elastic deformation, and there is no plastic strain. When the fault displacement is $1.2 \mathrm{~m}$, obvious buckling occurs only in section A, but there is no buckling in section B. It means that the buckling first appears on section A of the buried pipeline subjected to reverse fault displacement. Danger of a collapse 
of the buried pipeline is more serious as the fault displacement increases. In Fig. 4(b), when the fault displacement is less than $1.2 \mathrm{~m}$, there is no buckling phenomenon on the buried pipeline. But as the fault displacement increases, two wrinkles appear in section A, and only one wrinkle appears in section B.

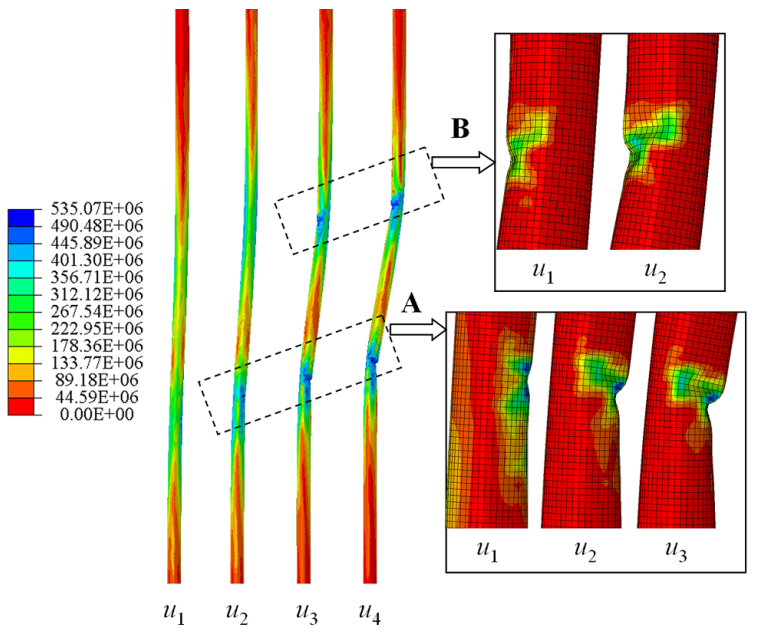

(a) Non-pressure pipes

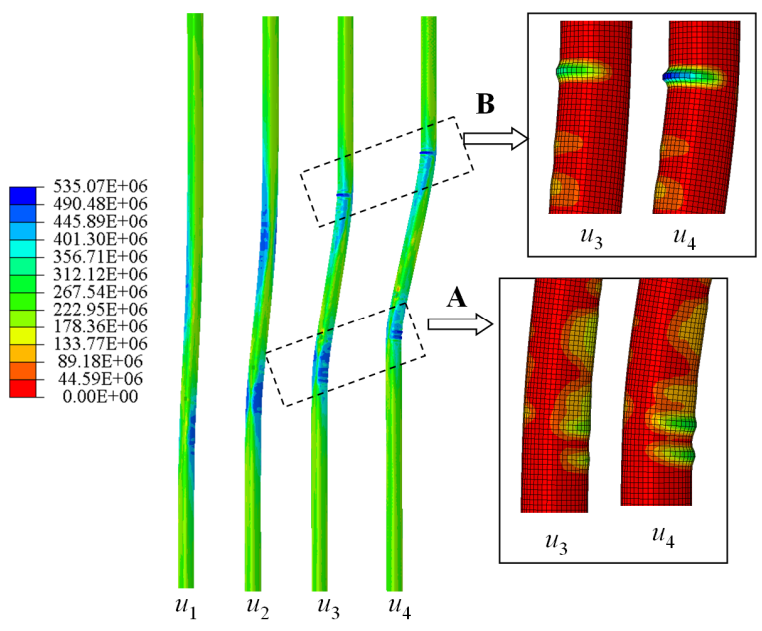

(b) Pressure pipes with $4.52 \mathrm{MPa}$

Fig. 4 Stress distribution and buckling modes of buried pipeline subjected to different fault displacements. $u_{1}=0.6 \mathrm{~m}, u_{2}=1.2 \mathrm{~m}, u_{3}=1.8 \mathrm{~m}, u_{4}=2.4 \mathrm{~m}$.

Deformation curves of non-pressure and pressure pipes subjected to different fault displacements are shown in Fig. 5. Displacement of the buried pipeline increases as the fault displacement increases. Shape of the deformation curve changes from the S-shape to the Zshape. There are two inflection points, which represent the two buckling positions. The two inflection points are not symmetrically distributed along the fault plane. In the case of the same fault displacement, deformation of the buckling position of the pressure pipe is more serious than in the case of the non-pressure pipe.

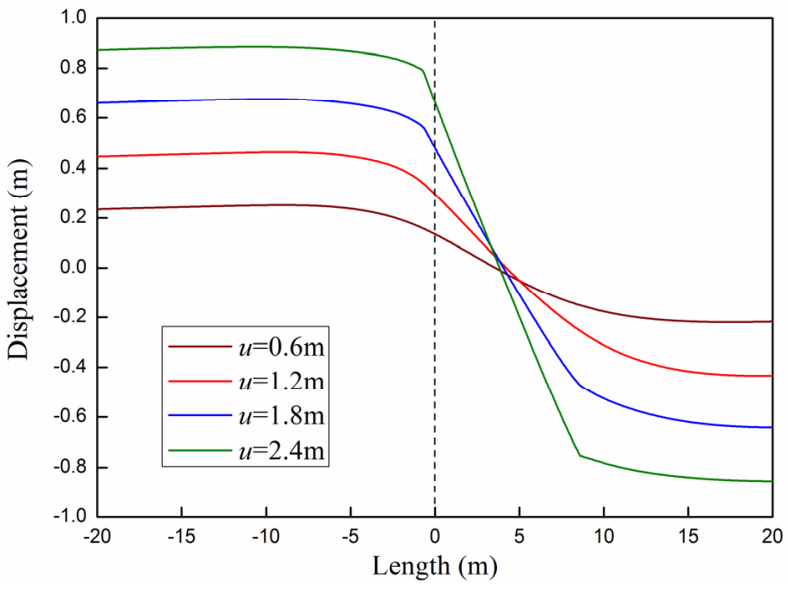

(a) Non-pressure pipes

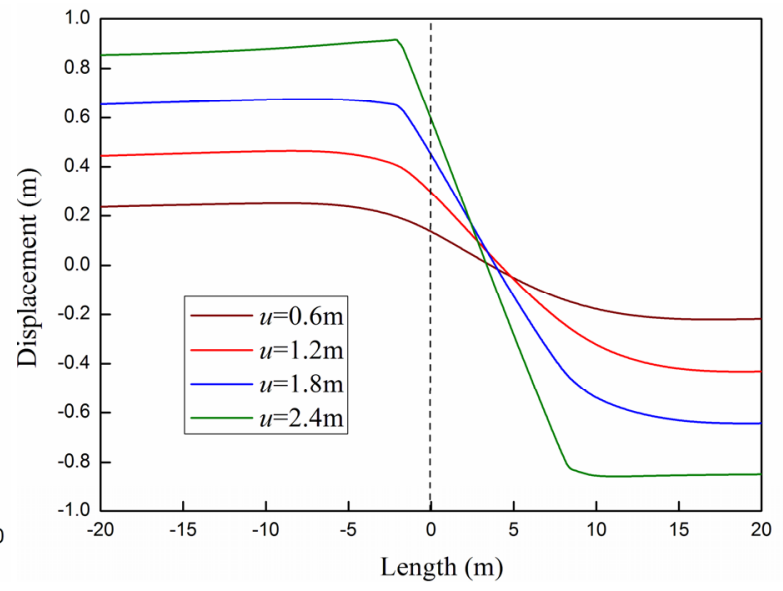

(b) Pressure pipes with 4.52MPa

Fig. 5 Deformation curves of buried pipeline subjected to different fault displacements.

Fig. 6 shows the maximum axial strain curve of the buckling locations along with fault displacement. As the fault displacement increases, axial strains of non-pressure and pressure buried pipes increase. The fault displacement process can be divided into three stages. There is no buckling on the buried pipeline in the first stage $(u \leq 1.2 \mathrm{~m})$. So, the change rate of the axial strain is small in this stage. The second stage $(1.2<u \leq 1.8 \mathrm{~m})$ is a transition stage. Buckling appears on the buried pipeline, but the buckling modes are uncertain. As the fault displacement increases, strain energy is redistributed and the buckling mode is more serious. 
So, the wave of the axial strain is big in this stage. Curve change of the axial strain is smooth in the third stage $(u>1.8 \mathrm{~m})$. For non-pressure pipes, the maximum axial strain of section $\mathrm{A}$ is greater than that of section $\mathrm{B}$. But for the pipes under the pressure of $4.52 \mathrm{MPa}$, the maximum axial strain of section A is greater than that of section B when the fault displacement is less than $1.5 \mathrm{~m}$. When the fault displacement is greater than $1.5 \mathrm{~m}$, the maximum axial strain of section $\mathrm{B}$ is greater than that of section $\mathrm{A}$. For section $\mathrm{A}$, the axial strain difference between non-pressure and pressure pipes is greatly affected by the fault displacement. For section B, the axial strain of the pressure pipes is greater than that of the non-pressure pipes.

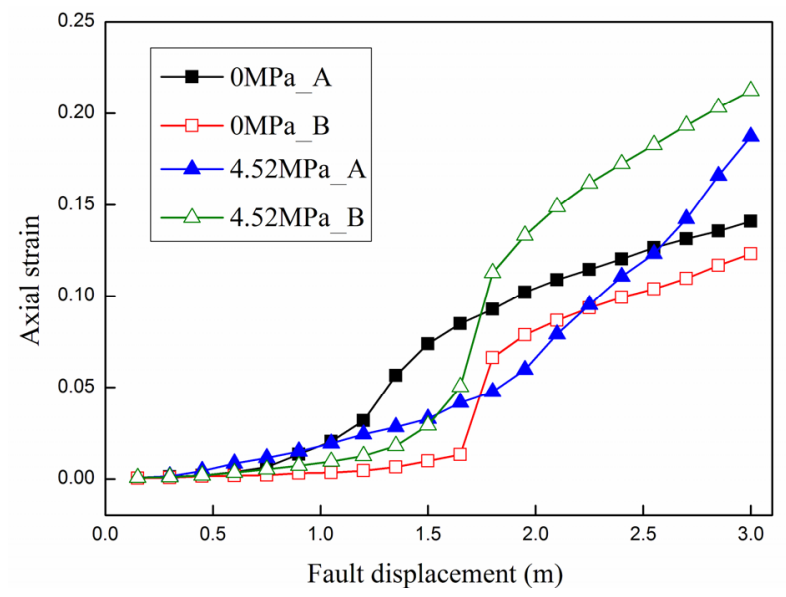

Fig. 6 Axial strain curve of buckling locations and fault displacement

Fig. 7 shows axial strain distributions of buried non-pressure and pressure pipes along the axial direction subjected to different fault displacements. The axial strains of the highest point of section A and the lowest point of section B are tensile strains. Strain waves appear at the lowest point of section A and the highest point of section B. The fault displacement has a small effect on the maximum strain position of the buried pipeline. The axial strain of the buried pipeline increases as the fault displacement increases.

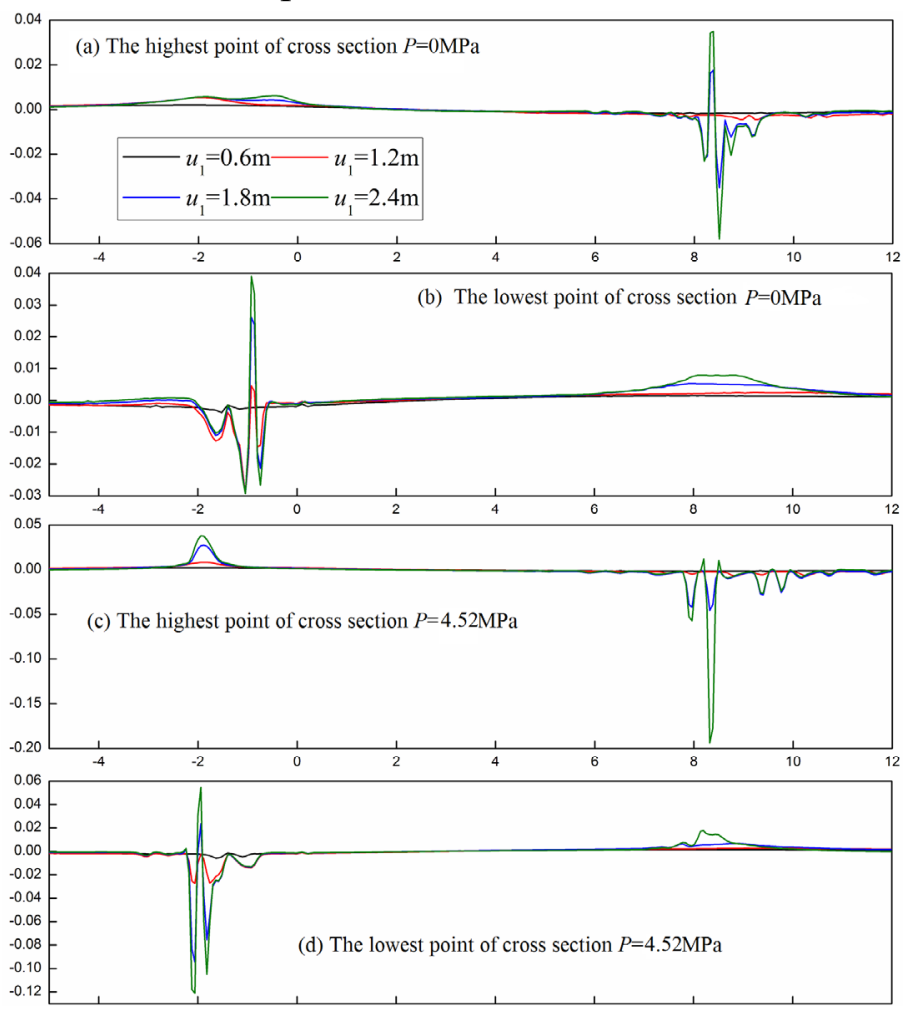

Fig. 7 Axial strain distributions of buried pipeline along axial direction subjected to different fault displacements. 


\subsection{Wall thickness effect}

Fig. 8 shows the von Mises stress distribution and buckling modes of non-pressure and pressure buried pipes with different wall thicknesses. For the non-pressure pipes (as shown in Fig. 8(a)), buckling disappears as the wall thickness increases. High stress of section B increases as the wall thickness increases. When the wall thickness is greater than $12 \mathrm{~mm}$, there is no buckling in section B. The stress of the pipeline along the fault plane becomes smaller as the wall thickness increases. Buckling of a buried pipeline with a smaller wall thickness subjected to reverse fault displacement is more serious.

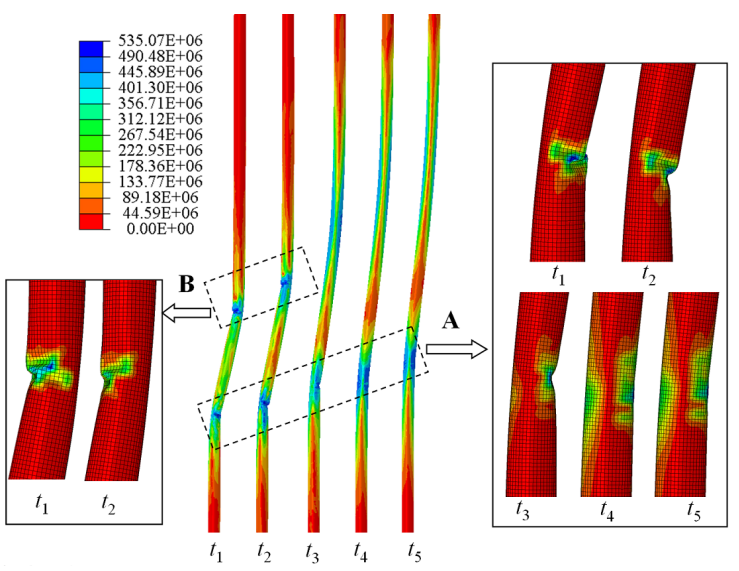

(a) Non-pressure pipes

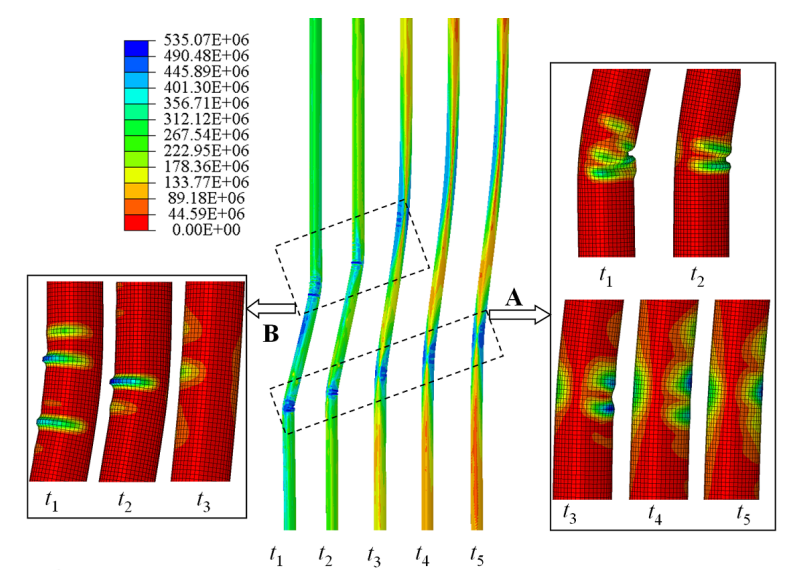

(b) Pressure pipes under pressure of $4.52 \mathrm{MPa}$

Fig. 8 Stress distribution and buckling modes of buried pipes with different wall thicknesses. $t_{1}=6 \mathrm{~mm}, t_{2}=8 \mathrm{~mm}$, $t_{3}=12 \mathrm{~mm}, t_{4}=16 \mathrm{~mm}, t_{5}=18 \mathrm{~mm}$.

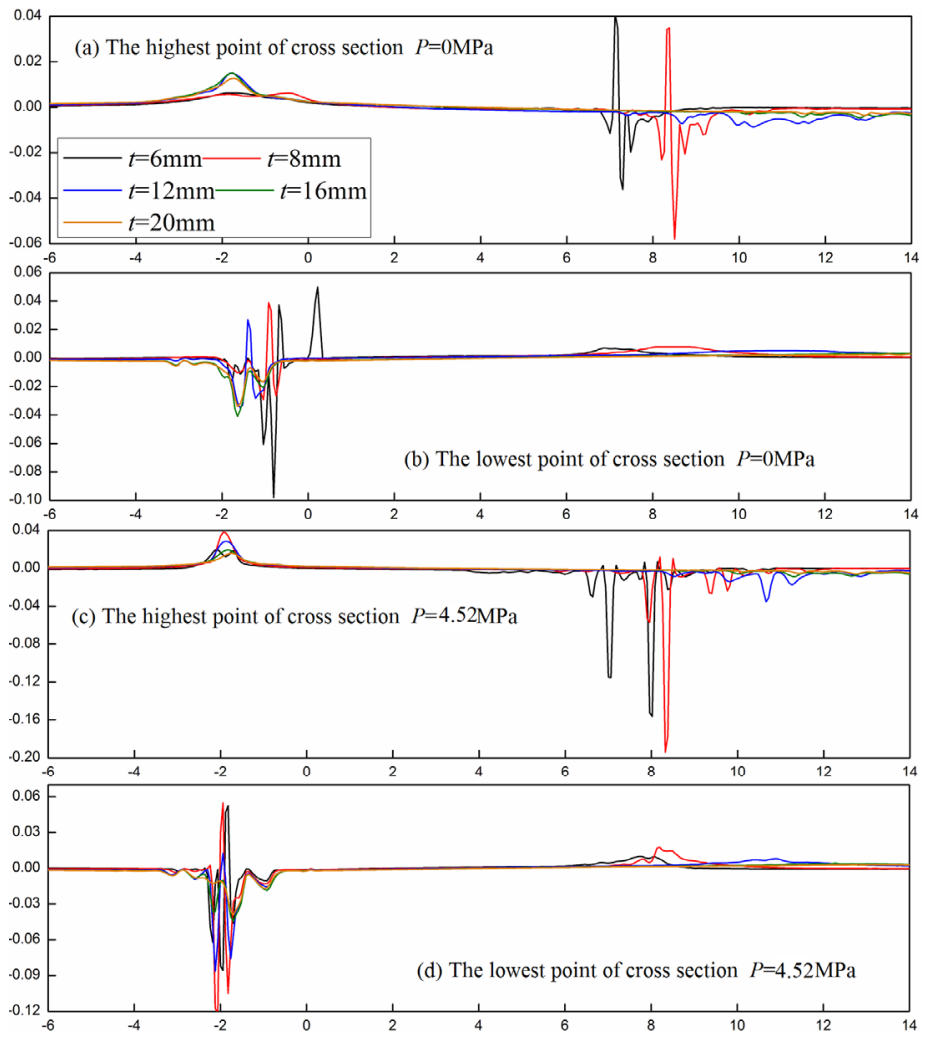

Fig. 9 Axial strain distribution of buried pipes with different wall thicknesses along axial direction.

For the pressure pipes (as shown in Fig. 8(b)), stress of non-buckled pipeline decreases as the wall thickness increases. Buckling phenomenon of the buried pipeline disappears as the wall thickness increases. The wrinkle amplitude decreases also. The deformation curve of the 
buried pipeline is more smooth as the wall thickness increases. Because of that the greater wall thickness can enhance the stiffness of buried pipeline. Therefore, the buried pipeline with a greater wall thickness is safer when subjected to reverse fault displacement.

Axial strain distribution of the buried pipeline along the axial direction is shown in Fig. 9. For non-pressure pipes (Fig. 9(a)(b)), axial strains of the highest point of section A and the lowest point of section B are tensile strains. But strain waves appear at the lowest point of section $\mathrm{A}$ and the highest point of section $\mathrm{B}$, because collapses appear at those parts. At the highest point of section $\mathrm{B}$, the maximum strain position gradually moves to the right side as the wall thickness increases. The amplitude of the strain wave also decreases. When the wall thickness is greater than $12 \mathrm{~mm}$, the axial strain is compressive strain and it is very small. At the lowest point of section A, the maximum strain position gradually moves to the left side and the amplitude of the strain wave decreases as the wall thickness increases. When the wall thickness is greater than $16 \mathrm{~mm}$, the axial strain is compressive strain.

For pressure pipes (Fig. 9(c)(d)), wall thickness has a small effect on the position of the maximum strain of section $\mathrm{A}$. The maximum strain position of section $\mathrm{B}$ gradually moves to the right side as the wall thickness increases. No matter whether in section A or section B, the maximum axial strain first increases and then decreases as the wall thickness increases. Because of that there will be more wrinkles to decrease the maximum strain by absorbing strain energy when the wall thickness is small.

\subsection{Burial depth effect}

Fig. 10 shows the von Mises stress distribution of the pressure pipes buried at different depths. Burial depth has a small effect on the stress distribution of the buried pipeline. But the distance between the two buckling locations decreases as the burial depth increases.

Fig. 11 shows the maximum axial strain of the pipeline at different burial depths. The maximum axial strain of the pipeline increases as the burial depth increases. For shallow buried pipelines, the hump phenomenon may appear on the ground surface under the action of the reverse fault. For the pipeline buried at a deeper depth, the constraint force caused by the surrounding soil is great. Therefore, the pipelines buried at a deeper depth are prone to failure.

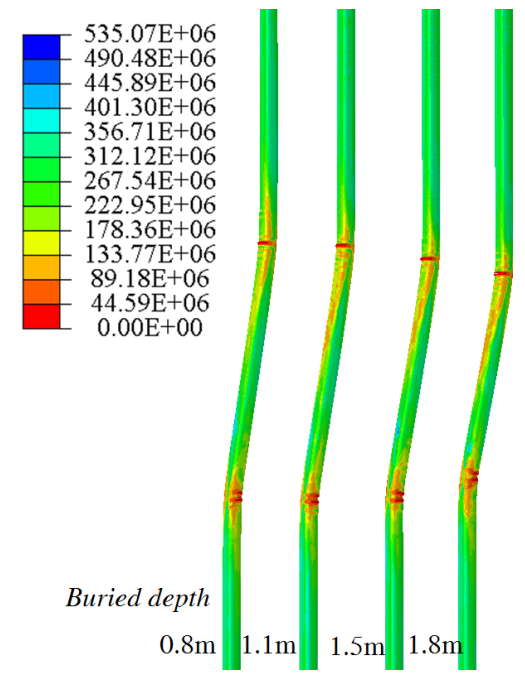

Fig. 10 Stress distribution of the pipeline

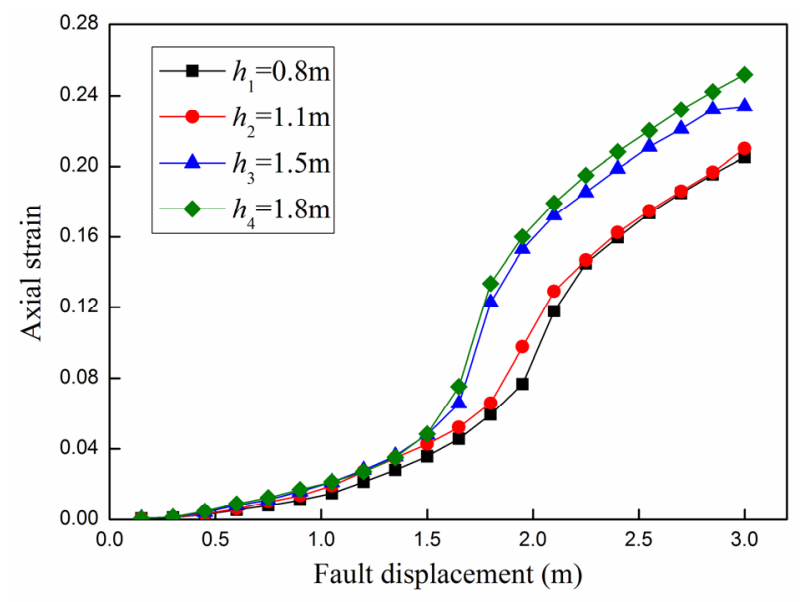

Fig. 11 The maximum axial strain at different buried depths

\subsection{Stratum material effect}

Let us assume that materials of the backfill soil and the stratum are the same. Fig. 12 shows the stress distributions of the pipeline buried in soil and rock stratum subjected to reverse fault displacement. For non-pressure pipes, the stratum material has a small effect on 
the stress distribution of the pipe. The distance between the two buckling locations of the pipe in the rock stratum is greater than that in the soil stratum. For pressure pipes, the stress of the pipe in the rock stratum is greater than that in the soil stratum.

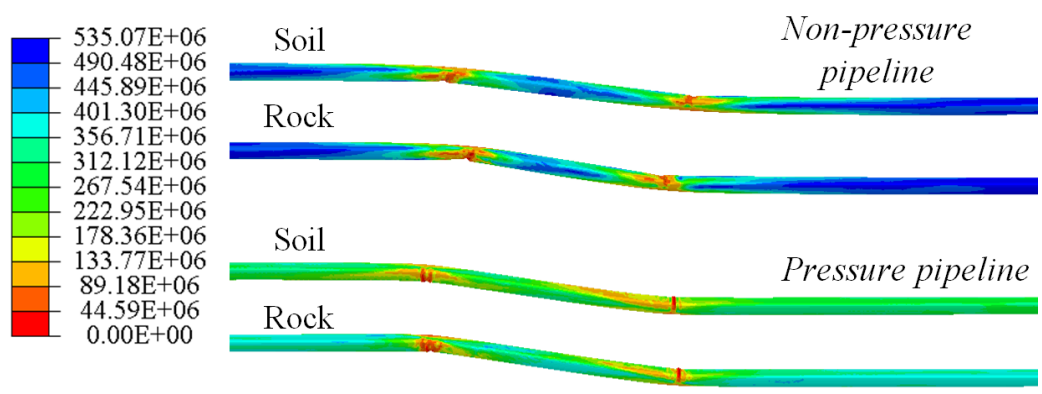

Fig.12 Stress distributions in pipes in different strata

Table 1 shows the maximum axial strain and equivalent plastic strain of the buried pipeline in the two stratum. No matter whether the pipes are non-pressure or pressure, the maximum axial strain and equivalent plastic strain of the pipes buried in the rock stratum are greater than those in the soil stratum. Therefore, the pipes buried in the rock stratum and subjected to reverse fault displacement are prone to failure.

Table 1 Maximum axial strain and equivalent plastic strain

\begin{tabular}{|c|c|c|c|}
\hline $\begin{array}{c}\text { Stratum } \\
\text { material }\end{array}$ & Internal pressure & Axial strain & $\begin{array}{c}\text { Equivalent } \\
\text { plastic strain }\end{array}$ \\
\hline \multirow{2}{*}{ Soil } & 0 & 0.0947 & 0.0100 \\
\cline { 2 - 4 } & $0.8 P_{\max }$ & 0.1424 & 0.1538 \\
\hline \multirow{2}{*}{ Rock } & 0 & 0.1145 & 0.1324 \\
\cline { 2 - 4 } & $0.8 P_{\max }$ & 0.1634 & 0.1704 \\
\hline
\end{tabular}

\section{Conclusions}

(1) There are two buckling locations on the buried pipeline subjected to reverse fault displacement in the rock stratum, and the buckling modes of the pipeline with different internal pressures are different. The two buckling locations are not symmetrically distributed along the fault plane. When the internal pressure is low, collapse appears. The buckling mode changes to wrinkling as the internal pressure increases, and the axial strain of section B of the pipeline increases. But there are two volatilities for the axial strain curve of section A. The pipes buried in the rock stratum and subjected to reverse fault displacement are more prone to failure than those buried in the soil stratum.

(2) The buckling phenomenon becomes more serious as the fault displacement increases. Buckling first appears in section A of the non-pressure pipes subjected to reverse fault displacement. Deformation of the pipeline increases as the fault displacement increases. The shape of deformation curves changes from the S-shape to the Z-shape. The process of pipeline deformation can be divided into three stages. There is no buckling on the buried pipeline in the first stage $(u \leq 1.2 \mathrm{~m})$. Buckling appears on the buried pipeline in the transition stage $(1.2<\mathrm{u} \leq 1.8 \mathrm{~m})$, but the buckling modes are uncertain. The curve change of axial strain is smooth in the third stage $(u>1.8 \mathrm{~m})$. Fault displacement has a small effect on the maximum strain position of the pipeline.

(3) Buckling disappears as the wall thickness increases, and the deformation curve of the buried pipeline is more smooth. Buckling of the buried pipeline with a smaller wall thickness subjected to reverse fault displacement is a more serious case. The maximum strain 
position of section B gradually moves to the side as the wall thickness increases. But the maximum axial strain of the pressure pipes first increases and then decreases.

\section{ACKNOWLEDGMENTS}

This research was supported by the Science and Technology Innovation Talent Engineering Project of Sichuan Province (No.2015097).

\section{REFERENCES}

[1] Hou, C.L.: Analysis method of the response of buried pipelines crossing fault to the fault rupture, Institute of Geophysics, China Earthquake Administration, Beijing, 2006.

[2] Wang, B: Study on analytical methods of buried steel pipelines under active faults, Dalian University of Technology, Dalian, 2011.

[3] Zhu, Q.J., Liu, Y.L.: Analysis of buried pipeline damage affected by pip-soil friction and pipe radius. Earthquake Eng. Eng. Vibr., 26(3), 197-199, 2006.

[4] Ma, Z.M., Feng, Q.M.: Seismic research and practice on buried pipeline crossing fault. World Earthquake Eng., 8(3), 24-31, 2002.

[5] Newmark, N.M., Hall, W.J.: Pipeline design to resist large fault displacement. Proceedings of US Conference on Earthquake Engineering, Ann Arbor, Michigan.416-425,1975

[6] Kennedy, R.P., Chow, A.M., Williamson, R.A.: Fault movement effects on buried oil pipeline. Transp. Eng. J., 103, 617-633, 1977.

[7] Wang, L.R.L., Yeh, Y.H.: A refined seismic analysis and design of buried pipeline for fault movement. Earthquake Eng. Struct. Dyn., 13, 75-96, 1985. DOI: 10.1002/eqe.4290130109

[8] Zhang, J., Liaing, Z., Han, C.J.: Finite element analysis of wrinkling of buried pressure pipeline under strike-slip fault. Mech., 21(3), 180-186, 2015. DOI: 10.5755/j01.mech.21.3.8891

[9] Zhang, J., Liaing, Z., Han, C.J.: Numerical simulation of buckling behavior of the buried steel pipeline under reverse fault displacement. Mech. Sci., 6, 203-210, 2015. DOI: 10.5194/ms-6-203-2015

[10] Wang, S.F., Yin, Y.P., Men, Y.M.: In-situ test and numerical analysis of skid resistance for micropile to loess landslide. Hydrogeol. Eng. Geol., 37, 22-26, 2010.

[11] Vazouras P., Karamanos S.A., Dakoulas P.: Mechanical behavior of buried steel pipes crossing active strike-slip faults. Soil Dyn. Earthquake Eng., 41, 164-180, 2012. DOI: 10.1016/j.soildyn.2012.05.012

[12] Vazouras P., Karamanos S.A., Dakoulas P.: Finite element analysis of buried steel pipelines under strikeslip fault displacements. Soil Dyn. Earthquake Eng., 30, 1361-1376, 2010.

DOI: $10.1016 /$ j.soildyn.2010.06.011

[13] American Society of Mechanical Engineers. Gas transmission and distribution piping systems, ANSI/ASME B31.8, New York, 2007.

[14] Zhang, J., Liaing, Z., Han, C.J.: Buckling behavior analysis of buried gas pipeline under strike-slip fault displacement. J. Nat. Gas Sci. Eng., 21, 921-928, 2014. DOI: 10.1016/j.jngse.2014.10.028

Submitted: $\quad$ 20.7.2015

Accepted: $\quad 20.9 .2016$
Jie Zhang

E-mail: longmenshao@163.com

Zheng Liang

Han Zhang

School of Mechatronic Engineering

Southwest Petroleum University,

Chengdu, China, 610500 